\title{
Minimally invasive sutureless and rapid deployment aortic valve replacement: the new benchmark for aortic valve surgery?
}

\author{
Francesco Pollari, Theodor Fischlein \\ Department of Cardiac Surgery, Klinikum Nürnberg - Paracelsus Medical University, Nuremberg, Germany \\ Correspondence to: Francesco Pollari, MD, PhD. Department of Cardiac Surgery, Klinikum Nürnberg - Paracelsus Medical University, Breslauer \\ Strasse 201-90471 Nuremberg, Germany. Email: francesco.pollari@klinikum-nuernberg.de.
}

Submitted Dec 17, 2019. Accepted for publication Jan 15, 2020.

doi: 10.21037/acs-2019-surd-175

View this article at: http://dx.doi.org/10.21037/acs-2019-surd-175

The advent of minimally invasive sutureless and rapid deployment aortic valve replacement (MI-SURD-AVR) was made possible by the synergy of many techniques—and technologies as well-that together contributed to achieve the most significant evolution of the original technique first described by Harken et al. in 1962 (1). However, even more important are the reasons that motivated these technical advancements-fostering the spirit of innovation typical of the founding fathers of cardiac surgery-including (I) lengthening of life expectancy, resulting in higher fragility and comorbidity burden, (II) changes in the etiology of aortic valve disease, with the transition from rheumatic to calcific degeneration, and (III) the need for improving patient compliance (2). These key features mark the differences in AVR between the past and the present century, and promoted the development of MI-SURD-AVR. In order to address these needs, both minimally invasive accesses (mini-J sternotomy and right anterior minithoracotomy) have been conceived, and new prostheses have also been developed. These two major advances in the field of cardiac surgery were applied to the same category of patients, and strengthened their effectiveness mutually. The minimally invasive approach is associated with high levels of patient satisfaction, because patients not only benefit from a limited skin incision, but also experience lower postoperative pain, fewer blood product transfusions, reduced postoperative ventilation time, faster mobilization, and reduced stay in an intensive care unit (3). Despite the slow pace of acceptance of MI-AVR within the cardiac surgery community, signs of change are being observed. A report by the German cardiac surgery society recorded $34.1 \%$ patients undergoing AVR performed by partial sternotomy in 2018 (4), as compared to $19.7 \%$ in 2013 (5).
Without underestimating the role of the advent of transcatheter aortic valve implantation (TAVI), the cause of this shift is also to be found in the growing volume of scientific evidence. After the first small and underpowered studies, the minimally invasive approach has increasingly shown better outcomes than traditional surgery in larger multicenter studies (6). Nevertheless, a randomized trial is still lacking.

The inherent technical difficulties of MI-AVR for the operators (narrow spaces and longer operating times) can effectively be reduced by the use of SURD prostheses. These new prosthetic valves also provide an obvious surgical advantage for patients with small and calcified annuli, andby shortening surgical times-for high-risk patients, who can benefit most from the positive aspects of minimally invasive access. The advantages deriving from this synergy (minimally invasive access and use of SURD prostheses) do not simply add up in an arithmetical, but in a logarithmic manner. These new-generation prostheses are currently on the market, including the sutureless Perceval valve (LivaNova Canada Corp., Burnaby, Canada) and the rapid-deployment Intuity valve (Edwards Lifesciences, Irvine, CA, USA). With different structures and anchoring systems, they have proved to confer small but significant advantages in different clinical scenarios. The Perceval sutureless aortic valve is a collapsible bioprosthesis with no need for suture anchorage, making it ideal for lateral thoracotomy accesses, where operating spaces are minimized, as well as for extremely calcified and small aortic roots. In contrast, the Intuity valve is implanted using three guiding sutures but is not collapsible, which makes it less suitable in the above mentioned scenarios. On the other hand, it has a remarkably smaller stent and a totally intra- or sub-annular anchoring stent frame, making 
it more suitable in patients with ascending aorta dilation or high sinotubular junction/annulus ratio. These new prostheses, however, are not without new challenges. In particular, the intra-annular design-similar to the TAVI prostheses-was found to be associated with a higher incidence of conduction disturbances, which nonetheless can be substantially reduced by adopting several simple surgical "tricks", as previously demonstrated by our group (7). Given that these new prostheses have only recently become available, it is not surprising that special procedural measures are necessary. A randomized study on the advantages of sutureless versus conventional prostheses, the first ever in cardiac surgery in 30 years, is currently underway, and the preliminary data will be presented in the coming months (Perceval Sutureless Implant Versus Standard-Aortic Valve Replacement (PERSIST-AVR), ClinicalTrials.gov Identifier NCT02673697) (8). Future challenges for the application of SURD prostheses include aortic valve insufficiency, endocarditis, as well as bicuspid anatomy. In such circumstances, challenges are mostly related to the structural alterations of the aortic annulus, which is the anchor point of the current prosthetic models. At present, caution has slowed the availability of broad evidence in this setting, despite some favorable reports on bicuspid aortic valves (9). Additionally, the wider application of SURD prostheses in younger patients is still limited by the lack of data about their long-term durability.

Interestingly, up to now, randomized controlled trials have only compared TAVI to traditional AVR, without taking into account the above described advances in aortic valve surgery. In order to set up our standards and to mark the direction for future development, benchmarks are important. If every age deserves a properly efficient solution for its problems, we can conclude that today, sutureless and rapid deployment valves-in combination with minimally invasive surgery - are the benchmark for the treatment of patients undergoing isolated AVR.

\section{Acknowledgments}

None.

\section{Footnote}

Conflicts of Interest: TF is consultant for LivaNova. FP has no conflicts of interest to declare.

Open Access Statement: This is an Open Access article distributed in accordance with the Creative Commons Attribution-NonCommercial-NoDerivs 4.0 International License (CC BY-NC-ND 4.0), which permits the noncommercial replication and distribution of the article with the strict proviso that no changes or edits are made and the original work is properly cited (including links to both the formal publication through the relevant DOI and the license). See: https://creativecommons.org/licenses/by-nc-nd/4.0/.

\section{References}

1. Harken DE, Taylor WJ, Lefemine AA, et al. Aortic valve replacement with a caged ball valve. Am J Cardiol 1962;9:292-9.

2. Iung B, Cachier A, Baron G, et al. Decision-making in elderly patients with severe aortic stenosis: why are so many denied surgery? Eur Heart J 2005;26:2714-20.

3. Young CP, Sinha S, Vohra HA. Outcomes of minimally invasive aortic valve replacement surgery. Eur J Cardiothorac Surg 2018;53:ii19-ii23.

4. Beckmann A, Meyer R, Lewandowski J, et al. German Heart Surgery Report 2018: The Annual Updated Registry of the German Society for Thoracic and Cardiovascular Surgery. Thorac Cardiovasc Surg 2019;67:331-44.

5. Funkat A, Beckmann A, Lewandowski J, et al. Cardiac surgery in Germany during 2013: a report on behalf of the German Society for Thoracic and Cardiovascular Surgery. Thorac Cardiovasc Surg 2014;62:380-92.

6. Paparella D, Malvindi PG, Santarpino G, et al. Full sternotomy and minimal access approaches for surgical aortic valve replacement: a multicentre propensitymatched study. Eur J Cardiothorac Surg 2020;57:709-16.

7. Vogt F, Moscarelli M, Nicoletti A, et al. Sutureless Aortic Valve and Pacemaker Rate: From Surgical Tricks to Clinical Outcomes. Ann Thorac Surg 2019;108:99-105.

8. Lorusso R, Folliguet T, Shrestha M, et al. Sutureless versus Stented Bioprostheses for Aortic Valve Replacement: The Randomized PERSIST-AVR Study Design. Thorac Cardiovasc Surg 2020;68:114-23.

9. Nguyen A, Fortin W, Mazine A, et al. Sutureless aortic valve replacement in patients who have bicuspid aortic valve. J Thorac Cardiovasc Surg 2015;150:851-7.

Cite this article as: Pollari F, Fischlein T. Minimally invasive sutureless and rapid deployment aortic valve replacement: the new benchmark for aortic valve surgery? Ann Cardiothorac Surg 2020;9(4):328-329. doi: 10.21037/acs-2019-surd-175 